\title{
RUNX1 gene expression in Egyptian acute myeloid leukemia patients: may it have therapeutic implications?
}

\author{
Fadwa Said ${ }^{1 *}$, Roxan E. Shafik ${ }^{2}$ and Naglaa M. Hassan²
}

\begin{abstract}
Background: Acute myeloid leukemia represents the highest percentage of all adult acute leukemia variants. Runtrelated transcription factor1 (RUNX1), a transcription factor with a known tumor suppressor function, was recently reported as a tumor promoter in acute myeloid leukemia (AML). We investigated the role of RUNX1 gene expression level in Egyptian AML patients and delineated its clinical significance.

Results: We measured $R \cup N X 1$ gene expression level using reverse transcription-quantitative polymerase chain reaction and found that the RUNX1 gene expression level was significantly higher than the control group ( $\mathrm{p}<$ 0.001). Patients with FMS-like tyrosine kinase 3 internal tandem duplication (FLT3-ITD) mutations had a higher expression level of RUNX1 ( $p=0.023)$. The male patients expressed a significantly higher level of RUNX1 $(p=0.046)$.

Conclusions: The RUNX1 gene is highly expressed in Egyptian AML patients. It has a relation to FLT3-ITD, which may give a clue that patients carrying this mutation may benefit from new treatments that target $R U N X 1$ in the future. Further studies on a larger number of patients with different ethnic groups may give a clearer vision of the therapeutic implications of a new molecular target.
\end{abstract}

Keywords: Acute myeloid leukemia, RUNX1, Gene expression, Egypt

\section{Background}

To the best of our knowledge, there has been no comprehensive study investigating the incidence rate of acute myeloid leukemia (AML) in the country of Egypt. Each year, three to four new AML cases are reported per 100, 000 individuals. The prognosis of AML is highly variable despite intensive research for new markers and therapies [1]. Relapse is the most frequent cause of therapeutic failure $[2,3]$. Less than $50 \%$ of patients have a 5 -year overall survival rate (OS), and only $20 \%$ of the elderly survive 2 years [1].

Genetic and epigenetic alterations in the hematopoietic stem and progenitor cells cause aberrant proliferation and block differentiation (HSPCs), leading

\footnotetext{
* Correspondence: f2said@yahoo.com

${ }^{1}$ Clinical Pathology Department, Faculty of Medicine, Cairo University, Cairo, Egypt

Full list of author information is available at the end of the article
}

to different clinical types of AML [4]. Several studies have recognized various genes affected by the somatic mutations due to different AML subtypes [5, 6]. Mutations in the transcriptional regulator, additional sex combs like 1, tumor protein 53, and FMs-related tyrosine kinase 3 (FLT3) genes and specific chromosomal translocations (Breakpoint cluster region-Abelson murine leukemia viral oncogene homolog 1) were reported to predispose to AML [7]. The data from previous studies have helped in the elucidation of AML biology, facilitating better risk assessment while determining novel drug targets and therapeutic strategies $[5,6]$.

The RUNX1 gene has emerged as a novel therapeutic target for AML [8]. It belongs to a transcriptional regulator family called Runx that comprises three members: RUNX1, RUNX2, and RUNX3 [9]. It is located on chromosome 21 and is vital for the process of hematopoiesis [8]. It consists of a "Runt homology 
domain" (RHD) that facilitates the formation of the heterodimer of RUNX1 and PEBP2 $\beta$ that acts as a DNA binding and transcription factor [10].

RUNX1 gene activity is regulated via translational regulation, posttranslational modifications (PTM), and alternative splicing [11, 12].

First, the RUNX1 is known to be involved in the chromosomal translocation $(8 ; 21)$ that lead to the formation of RUNX1-RUNX1T1 (AML1-ETO) fusion gene and represents $10-22 \%$ of AML cases with maturation corresponding to the previous $\mathrm{FAB}$ class $\mathrm{M} 2$ and work as a diagnostic and favorable prognostic factor [13].

Theories state that reduced levels of RUNX1 activity contribute to the myeloid differentiation block in AML [4]. This was supported by several studies that have shown the tumor suppressor role of RUNX1 via various mouse models [14-17]. Furthermore, RUNX1 has been implicated in the inhibition of self-renewal programs in early HSPCs [18].

Conversely, during 2012, Hebestreit et al. studied a large cohort of AML patients and reported a significant increase in RUNX1 transcript levels in FLT3-ITD ${ }^{\text {pos }}$ samples [19]. This was confirmed during 2017 by Behrens et al., who wrote that upregulated and phosphorylated RUNX1 cooperates with FLT3-ITD to induce AML [4].

They revealed that RUNX1 downregulation promotes the differentiation of AML cells expressing FLT3-ITD. Therefore, the introduction of such mutations could act as a potential therapeutic strategy for AML patients with FLT3-ITD mutations [4].

Our study aims to evaluate the results of RUNX1 gene expression and elaborate its clinical significance in an Egyptian cohort of patients with de novo AML, giving special attention to $F L T$-ITD positive patients.

\section{Methods}

\section{Study group}

This study recruited 91 AML patients recently diagnosed at the Hematology Clinic, National Cancer Institute, Cairo, Egypt, from June 2015 till December 2018. For the control group, 14 healthy age- and sex-matched donors of the bone marrow transplantation unit were recruited. The patients included 50 males and 41 females between 18 and 65 (mean age, 35.5 years). Inclusion criteria are as follows: Egyptian, adult 18 years or more, and de novo AML. Exclusion criteria are as follows: patients less than 18 years, patients who started treatment, and non-Egyptian.

All remaining patients' peripheral blood was analyzed for measuring different blood parameters, such as hemoglobin $(\mathrm{Hb})$, platelets count, and total leukocyte count (TLC). Blasts were counted in bone marrow samples and peripheral blood. Based on the FrenchAmerican-British (FAB) classification of AML, the patients were divided into subgroups [20]. Cytogenetic and gene mutation analyses for detecting chromosomal abnormalities, FLT3-ITD, and NPM mutations were done for all patients by reverse transcriptase-polymerase chain reaction and qualitative real-time $\mathrm{PCR}$, respectively (Table 1).

The institutional review board of the National Cancer Institute, Cairo University, approved the study's protocol and we followed the Helsinki guidelines for the protection of human subjects. Written informed consent was obtained from all participants.

Table 1 Laboratory characteristics of the AML group $(n=91)$

\begin{tabular}{ll}
\hline & Value \\
\hline Total leukocytic count $\left(\times 10^{3} / \mathrm{mm}^{3}\right)$ & $38.9(1.0-440.0)$ \\
Hemoglobin concentration $(\mathrm{gm} / \mathrm{dL})$ & $8.0 \pm 1.8$ \\
Platelet count $\left(\times 10^{3} / \mathrm{mm}^{3}\right)$ & $35.0(5.0-297.0)$ \\
Peripheral blood blasts (\%) & $51.0(0.0-98.0)$ \\
Bone marrow blasts (\%) & $70.0(0.0-97.0)$
\end{tabular}

\section{FAB classification}

M1

$11(12.1 \%)$

$\mathrm{M} 2$

$38(41.8 \%)$

$\mathrm{M} 4$

$31(34.1 \%)$

M5

$10(11.0 \%)$

M7

$1(1.1 \%)$

BM cellularity

Hypercellular

$68(74.7 \%)$

Normocellular

12 (13.2\%)

Hypocellular

$5(5.5 \%)$

FLT3-ITD mutation

14 (15.4\%)

NPM mutation

9 (39.1\%)

Molecular markers

-ve

77 (84.6\%)

+ve

$14(15.4 \%)$

inv (16)

$8(8.8 \%)$

$\mathrm{t}(8,21)$

$1(1.1 \%)$

$t(8,21), t(9,22)$

$1(1.1 \%)$

$t(8: 21)$

4 (4.4\%)

Genetics

Abnormal

$24(26.4 \%)$

Normal

$67(73.6 \%)$

Genetic risk (ELN)

Favorable

18 (19.8\%)

Intermediate

51 (56.0\%)

Adverse

$22(24.2 \%)$ 


\section{Definitions}

Refractoriness is defined as the failure to achieve CR following completion of initial treatment, with evidence of persistent leukemia in examinations of blood or bone marrow.

Relapse is defined as $\geq 5 \%$ bone marrow blasts, the reappearance of blasts in the blood, or extramedullary disease development.

OS is defined as the time from diagnosis to death from any cause. Data from patients who were alive on the date of the last follow-up were censored on that date. Progression-free survival (PFS) is defined as the time from therapy initiation until documented progression or death. For patients without disease progression at the time of analysis, the data were right-censored at the date of their last follow-up [21].

\section{Quantitative reverse transcriptase-PCR}

\section{Sample collection, RNA extraction, and CDNA formation}

Bone marrow samples $(1 \mathrm{ml})$ were collected on EDTA from patients with AML. Bone marrow was treated with erythrocyte lysis solution; without culture, leukocytes were collected and stored in buffer RLT $\left(1 \times 10^{7}\right.$ leukocytes) at $-80{ }^{\circ} \mathrm{C}$ till use for RNA extraction.

We used QIAamp RNA extraction blood Mini kit (QIAGEN $^{\circ}$ Austin, TX, USA; catalog no. 52304) to extract total RNA from $1 \mathrm{~mL}$ culture of BM cells preserved on K-EDTA. We used spectrophotometer nano-drop (Quawell, Q-500, Scribner, USA) to assess the concentration and purity of RNA and kept it at $-80{ }^{\circ} \mathrm{C}$ until further use.

We used High Capacity cDNA Reverse Transcription Kit (Applied Biosystems, Thermo Fisher Scientific, USA; catalog no. 4368814) to reverse transcribe the extracted RNA. Again, the spectrophotometer nano-drop was used to qualify and quantify the complementary DNA (cDNA) and kept at $20^{\circ} \mathrm{C}$.

\section{Molecular detection of RUNX1 gene expression}

RUNX1 mRNA expression was quantified using Taq$\mathrm{Man}^{\circ}$ Universal PCR Master Mix, 2Xconc (Cat No. 4440040, Thermo Fisher scientific, Applied Biosystems, USA), Taqman readymade gene expression assay, for RUNX1 mRNA (Hs02558380_S1; Thermo Fisher Scientific, USA, Cat No. 4331182) and $\beta$-actin [22]. The total reaction volume for PCR mix was $20 \mu \mathrm{L}$, and the PCR protocol was as follows: $95{ }^{\circ} \mathrm{C}$ for $10 \mathrm{~min}$ (polymerase activation), followed by 40 cycles of $95{ }^{\circ} \mathrm{C}$ for $30 \mathrm{~s}$ (denaturation), and $60{ }^{\circ} \mathrm{C}$ for $60 \mathrm{~s}$ (annealing and extension). The StepOne Real-Time PCR System (Applied Biosystems, Foster City, CA, USA) was used to detect the fluorescence. The following primers were used for quantitative PCR: RUNX15'-AGTGGAAGAGGGAAAA GC-3' (sense) and 5'-ATCCACTGTGATTTTGATGG-
3' (antisense) and $\beta$-Actin (control) 5'-GTGGGCCGCT CTAGGCACCAA-3' (sense) and 5'-CTCTTTGATG TCACGCACGATTTC-3' (antisense). Comparative Ct method $\left(2^{-\Delta \Delta C t}\right)$ was used to assess the relative RUNX1 expression level that was expressed as fold change normalized against $\beta$-Actin expression levels [23]. The median follow-up period was 7 months (range, 0.03-40.2 months).

\section{Treatment and follow-up}

The patients were treated with a standard induction regimen; an administration of cytarabine (100-200 mg/ $\mathrm{m}^{2} / \mathrm{d}$ ) for 7 days along with anthracycline or idarubicin $\left(12 \mathrm{mg} / \mathrm{m}^{2} /\right.$ days $)$ or daunorubicin $\left(45-90 \mathrm{mg} / \mathrm{m}^{2} /\right.$ days $)$ for 3 days. After one or two courses of induction chemotherapy, the individuals undergoing complete remission (CR) further received 2 to 6 cycles of high-dose cytarabine-based consolidation chemotherapy. Shortterm follow-up was done by complete blood count, bone marrow aspirate, flow cytometry, and molecular analysis.

\section{Statistical analysis}

IBM SPSS ${ }^{\bullet}$ Statistics version 22 (IBM ${ }^{\bullet}$ Corp., Armonk, NY, USA) was used for statistical analysis. Numerical data was represented as either median and range or mean and standard deviation. The qualitative data was represented as either percentage or frequency. The correlation between qualitative variables was evaluated by Fisher's exact test or Pearson's Chi-square test. In quantitative data, Student's t-test was used to compare two groups belonging to normally distributed data, and Mann-Whitney test (non-parametric t-test) was used for groups belonging to data not normally distributed. The correlation among numerical variables was analyzed using Spearman-rho method. The median value of the markers in the study group was used as the cutoff point with values above considered as over-expression and values below it as low expression. Markers were evaluated via calculating specificity, sensitivity, negative predictive value (NPV), positive predictive values (PPV), and overall accuracy. Kaplan-Meier method was used for survival analysis. The Logrank test was used to compare two survival curves. All the tests were two-tailed. Statistical significance is defined at $\mathrm{p}<0.05$.

\section{Results}

RUNX1 expression is significantly higher in AML cases

RUNX1 gene expression was measured in BM samples of de novo AML patients and 14 control subjects of the same age and sex. We found that the AML group showed significantly high RUNX1 gene expression levels than control cases $(\mathrm{p}<0.001)$ (Fig. 1). For AML patients, the fold change in RUNX1 expression ranged between 0.02 and 1382.78 (median, 16.81). Patients with values 


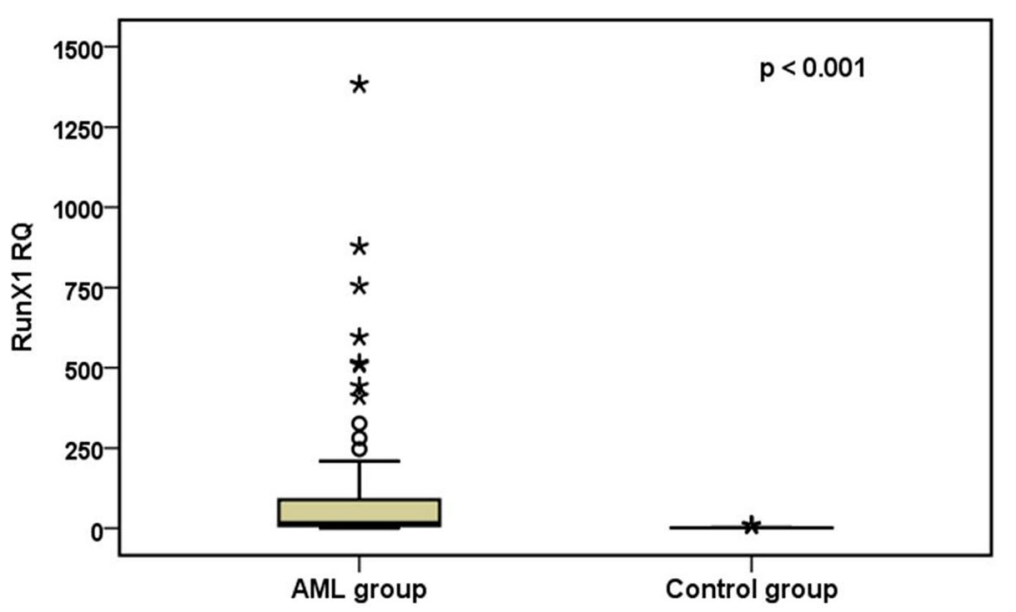

Fig. 1 Comparison between relative RUNX1 gene expression in AML cases and control group

below 16.81 were considered low expressions, while those with values above were deemed high expressions. None of the control groups was a high RUNX1 expression. Using this median value, specificity, sensitivity, negative predictive value, positive predictive value, and overall accuracy for diagnosis of AML were 100\%, 50.5\%, $23.7 \%, 100 \%$, and $57.1 \%$, respectively. The risk of AML had an odds ratio of 1.31 (95\% CI, 1.14-1.51).

\section{Characteristics of the AML patients by high and low expression levels of RUNX1}

As shown in Table 2, the male patients and the patients with mutant FLT3 exhibited significantly higher RUNX1 expression ( $\mathrm{p}=0.046$ and $\mathrm{p}=0.023$, Fig. 2 ), respectively (Fig. 2). In males, the median RUNX1 level was 30.0 (range, 0.2-878.2) compared to 16.0 (range, 0.8-1382.8) in females. RUNX1 expression was not significantly associated with other clinical, laboratory, and genetic characteristics of the studied group with RUNX1 expression status (Table 2).

\section{Relation of patients survival to the level of RUNX1 gene expression}

Overall survival (OS) is referred to the period from diagnosis of AML till the patient's death due to any cause. The patients that were alive on the last follow-up date were censored for that date. Progression-free survival (PFS) refers to the start of therapy until death or documented progression. The patients that did not exhibit any disease progression during the analysis period were censored on the last follow-up date [21].

During the period of the study, there were 54 patients that died. The median follow-up period was 7 months (range, 0.03-40.2 months). Median OS was 11.3 months, while the cumulative overall survival after 12 months was $46.6 \%$ (Table 2). Overall and event-free survival were not affected by RUNX1 expression ( $\mathrm{p}=0.804$ and $\mathrm{p}=0.314$, respectively) (Fig. 3a, b).

\section{Discussion}

In the last decade, the RUNX family was suggested as a tumor biomarker that plays a dual role in acute myeloid leukemia, which is why it is essential to continue with studies that discuss its importance and clinical significance in AML [24-26].

Translocations and mutations of the RUNX1 gene locus were reported to cause an increase or decrease in its function and induce leukemia [26-28].

Our study evaluated the expression levels of the RUNX1 gene in the Egyptian de novo AML patients. Previous human studies were conducted on Chinese and Polish people [29]. The findings of this study have to be seen in light of some limitations: a small number of cases and the short time of follow-up.

We want to clarify that out of $42 \%$ of the AML patients, which were classified as M2, translocation $\mathrm{t}(8 ; 21)$ was observed only in $6.6 \%$ of the cases. Therefore, the translocation-induced effect on the expression levels of RUNX1 might be associated only in only $6.6 \%$ of cases.

We found that RUNX1 expression was significantly higher in AML patients ( $\mathrm{p}<0.001)$. The same was reported by $\mathrm{Fu}$ et al., who estimated RUNX1 expression using microarrays on the bone marrow samples of 157 normal cytogenetic AML (CN-AML) in Chinese patients [30]. They reported that patients exhibited significantly higher RUNX1 expression $(\mathrm{P}<0.001)$. In our study, the patients with higher RUNX1 expression were more likely to harbor FLT3-ITD mutation than patients with lower RUNX1 expression $(\mathrm{p}=0.023)$. This indicated that, under high expression, RUNX1 could act as an oncogene that induces leukemogenesis and act as a surrogate marker for other mutations especially, FLT3-ITD. In 
Table 2 Characteristics of the AML patients by high and low expression levels of RUNX1

\begin{tabular}{|c|c|c|c|}
\hline & RUNX1 over-expressors $(n=46)$ & RUNX1 low-expressors $(\mathrm{n}=45)$ & $\mathrm{p}$ value \\
\hline Age (years) & $36.0 \pm 10.9$ & $34.9 \pm 12.3$ & 0.434 \\
\hline \multicolumn{4}{|l|}{ Sex } \\
\hline Male & $30(60.0 \%)$ & $20(40.0 \%)$ & \multirow[t]{2}{*}{0.046} \\
\hline Female & $16(39.0 \%)$ & $25(61.0 \%)$ & \\
\hline $\operatorname{TLC}\left(\times 10^{3} / \mathrm{mm}^{3}\right)$ & $50.7(1.0-440.0)$ & $25.1(1.7-281.7)$ & 0.191 \\
\hline $\mathrm{Hb}(\mathrm{gm} / \mathrm{dL})$ & $7.8 \pm 1.8$ & $8.3 \pm 1.7$ & 0.267 \\
\hline $\operatorname{PLT}\left(\times 10^{3} / \mathrm{mm}^{3}\right)$ & $32.0(6.0-208.0)$ & $35.0(5.0-297.0)$ & 0.923 \\
\hline PB blasts (\%) & $59.0(10.0-95.0)$ & $48.5(0.0-98.0)$ & 0.229 \\
\hline BM blasts (\%) & $72.0(30.0-97.0)$ & $70.0(0.0-95.0)$ & 0.282 \\
\hline \multicolumn{4}{|l|}{ FAB1 } \\
\hline $\mathrm{M} 1, \mathrm{M} 2$ & $27(55.1 \%)$ & $22(44.9 \%)$ & \multirow[t]{2}{*}{0.348} \\
\hline M4, M5, M7 & $19(45.2 \%)$ & $23(54.8 \%)$ & \\
\hline \multicolumn{4}{|l|}{ FLT3 } \\
\hline Mutant & $11(78.6 \%)$ & $3(21.4 \%)$ & \multirow[t]{2}{*}{0.023} \\
\hline Wild & $35(45.5 \%)$ & $42(54.5 \%)$ & \\
\hline \multicolumn{4}{|l|}{ NPM } \\
\hline Mutant & $5(55.6 \%)$ & $4(44.4 \%)$ & \multirow[t]{2}{*}{1.000} \\
\hline Wild & $7(50.0 \%)$ & $7(50.0 \%)$ & \\
\hline \multicolumn{4}{|l|}{ Molecular markers } \\
\hline$-v e$ & $39(50.6 \%)$ & 38 (49.4\%) & \multirow[t]{2}{*}{0.964} \\
\hline +ve & 7 (50.0\%) & 7 (50.0\%) & \\
\hline \multicolumn{4}{|l|}{ Genetics } \\
\hline Abnormal & $11(45.8 \%)$ & $13(54.2 \%)$ & \multirow[t]{2}{*}{0.590} \\
\hline Normal & 35 (52.2\%) & $32(47.8 \%)$ & \\
\hline \multicolumn{4}{|l|}{ Genetic risk } \\
\hline Favorable & 8 (44.4\%) & $10(55.6 \%)$ & \multirow[t]{3}{*}{0.363} \\
\hline Intermediate & 24 (47.1\%) & $27(52.9 \%)$ & \\
\hline Adverse & $14(63.6 \%)$ & 8 (36.4\%) & \\
\hline
\end{tabular}

TLC total leukocytic count, $H b$ hemoglobin concentration, PLT platelet count, PB peripheral blood, BM bone marrow

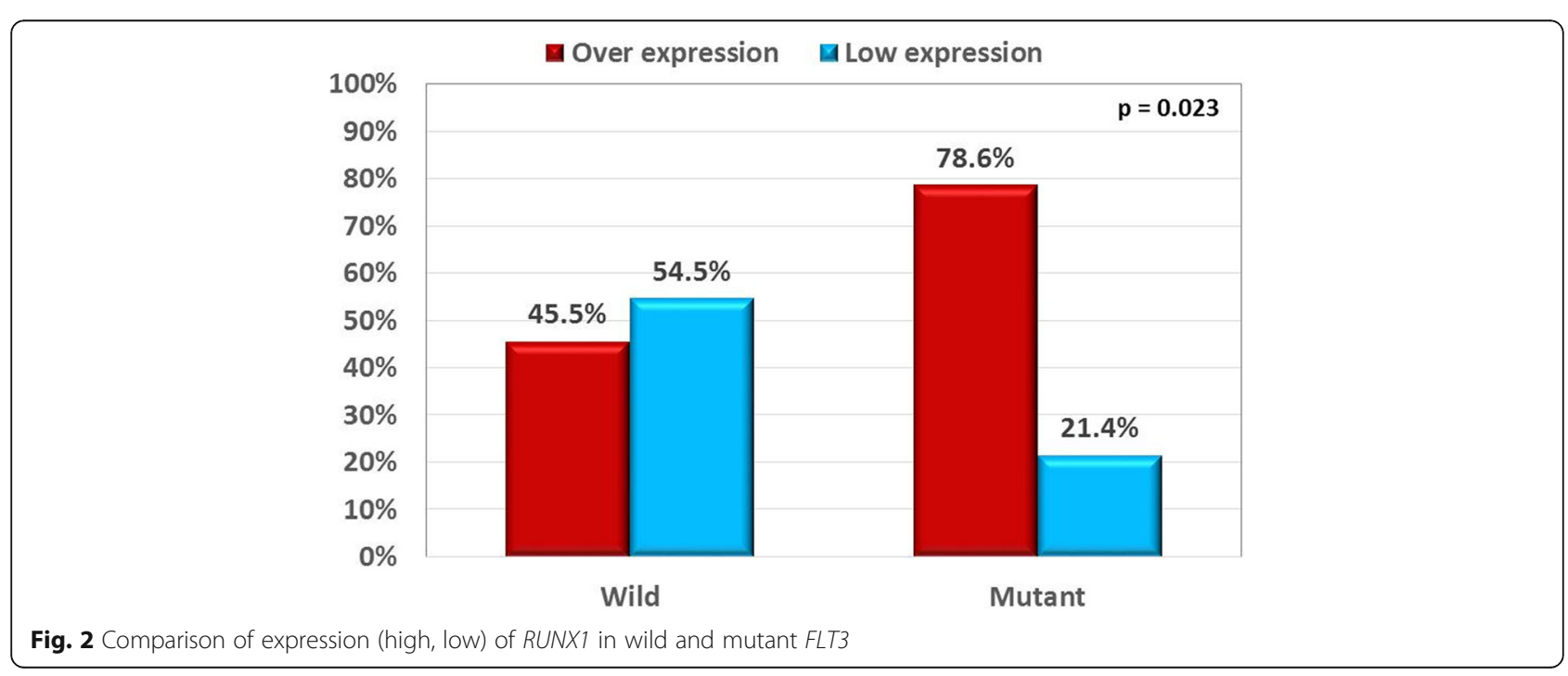



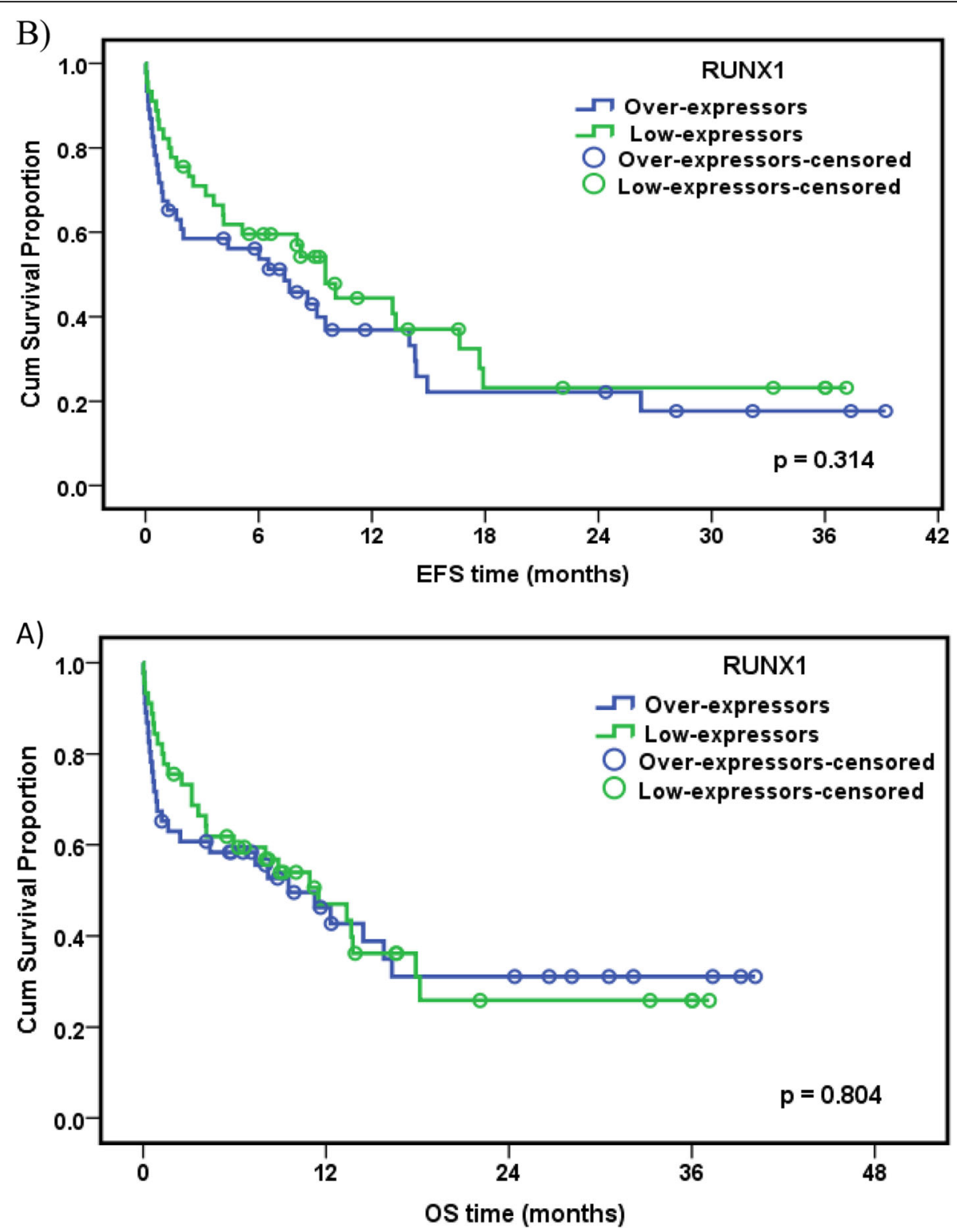

Fig. 3 a Overall survival and their relation to RUNX1 expression in the patients. $\mathbf{b}$ Event-free survival and their relation to RUNX1 expression in the patient

agreement with the previous results, Behrens et al. reported that, after upregulation and phosphorylation, RUNX1 could trigger AML in conjugation with FLT3ITD. Thus, suppression of RUNX1 could hold high potential as a therapeutic strategy that could markedly enhance the current therapeutic approaches, involving FLT3 inhibitors, by reversing the differentiation block and making therapy more effective [18].

Furthermore, we observed a significantly higher RUNX1 expression in male patients $(\mathrm{p}=0.046)$. This result was in contrast to Krygier et al., who reported in his study on 43 Polish de novo AML cases using RT qPCR analysis technique that RUNX1 significantly expressed in females [29]. This disagreement may be due to the difference in sample size or could be due to racial differences. In his study, Fu et al. reported that among the $157 \mathrm{CN}$-AML patients enrolled by them, the group of patients with higher $R U N X 1$ gene expression comprised a significantly higher proportion of patients with FAB M1 and M2 subtypes, compared to the group of patients with lower RUNX1 expression [30]. These results differed from our present study, where we found no association between the FAB subtypes and RUNX1 expression $(\mathrm{P}=0.348)$. Also, they reported that higher RUNX1 expression in CN-CML patients is associated with poorer PFS and OS $(\mathrm{p}=0.011$ and $\mathrm{p}=0.009$, 
respectively). However, in this study, we did not find any correlation between RUNX1 expression and FAB classification, OS, and PFS $(\mathrm{P}=0.348, \mathrm{P}=0.804, \mathrm{P}=$ 0.314 , respectively). This is similar to Krygier et al., who concluded that high expression of RUNX1 has no relation to FAB classification of AML and mortality [29]. Our study found no associations between ages, TLC, Hb, PLT, peripheral, and bone marrow blasts and different ELN genetic groups and the level of $R U N X 1$ expression.

In conclusion, RUNX1 is highly expressed in Egyptian AML patients and its downregulation may open a new hope for better therapeutic approaches in some cases, especially with FLT3 mutations. Males may have higher levels of RUNX1 expression. Future studies with larger sample size and longer follow-up may confirm these findings and find different correlations that could not be detected in this study.

\section{Abbreviations}

RUNX1: Runt-related transcription factor 1; AML: Acute myeloid leukemia; FLT3-ITD: FMS-like tyrosine kinase 3 internal tandem duplication; OS: Overall survival rate; HSPCs: Hematopoietic stem and progenitor cells; FLT3: FMsrelated tyrosine kinase 3; RHD: Runt homology domain;

PTM: Posttranslational modifications

\section{Acknowledgements}

None

\section{Declarations}

\section{Authors' contributions}

FSAM, RES, and NMH collected, analyzed, and interpreted the patient data. FSAM, RES, and NMH performed the examination and contributed majorly in writing the manuscript. The authors read and approved the final manuscript.

\section{Funding}

None

\section{Availability of data and materials}

Not applicable

\section{Ethics approval and consent to participate}

The institutional review board of National Cancer Institute, Cairo University, approved the protocol of the study and we followed the Helsinki guidelines for the protection of human subjects. Written informed consents were obtained from all participants. The reference number is not available.

\section{Consent for publication}

Not applicable

\section{Competing interests}

The authors declare that they have no competing interests.

\section{Author details}

${ }^{1}$ Clinical Pathology Department, Faculty of Medicine, Cairo University, Cairo, Egypt. ${ }^{2}$ Clinical Pathology Departement, National Cancer Institute, Cairo University, Cairo, Egypt.
Received: 27 February 2021 Accepted: 20 May 2021

Published online: 18 June 2021

\section{References}

1. Neemat K, Abd El-Gawad F, Desoky M et al (2013) CCAAT/enhancer binding protein a gene expression in Egyptian patients with acute myeloid leukemia. J Egyp Nat Cancer Inst 25:115-120

2. Alan B, Wetzler M, Lowenberg B (2011) Therapeutic advances in acute myeloid leukemia. J Clin Oncol 29:487-494

3. Patel JP, Gönen M, Figueroa ME, Fernandez $H$, Sun Z, Racevskis J, van Vlierberghe P, Dolgalev I, Thomas S, Aminova O, Huberman K, Cheng J, Viale A, Socci ND, Heguy A, Cherry A, Vance G, Higgins RR, Ketterling RP, Gallagher RE, Litzow M, van den Brink MRM, Lazarus HM, Rowe JM, Luger S, Ferrando A, Paietta E, Tallman MS, Melnick A, Abdel-Wahab O, Levine RL (2012) Prognostic relevance of integrated genetic profiling in acute myeloid leukemia. N Engl J Med 366(12):1079-1089. https://doi.org/10.1056/ NEJMoa1112304

4. Kira B, Maul K, Tekin N (2017) RUNX1 cooperates with FLT3-ITD to induce leukemia. J Exp Med 214:737-752

5. Marcucci G, Haferlach T, Döhner H (2011) Molecular genetics of adult acute myeloid leukemia: prognostic and therapeutic implications. J Clin Oncol 29(5):475-486. https://doi.org/10.1200/JCO.2010.30.2554

6. Cancer Genome Atlas Research Network (2013) Genomic and epigenomic landscapes of adult de novo acute myeloid leukemia. N Engl J Med 368(22): 2059-2074. https://doi.org/10.1056/NEJMoa1301689

7. Döhner H, Estey E, Grimwade D, Amadori S, Appelbaum FR, Büchner T et al (2017) Diagnosis and management of AML in adults: 2017 ELN recommendations from an international expert panel. Blood 129:424-447

8. Okuda T, Van Deursen J, Hiebert SW, Grosveld G, Downing JR (1996) AML1, the target of multiple chromosomal translocations in human leukemia, is essential for normal fetal liver hematopoiesis. Cell. 84(2):321-330. https://doi. org/10.1016/50092-8674(00)80986-1

9. Goyama S, Huang G, Kurokawa M, Mulloy JC (2015) Posttranslational modifications of RUNX1 as potential anticancer targets. Oncogene. 34(27): 3483-3492. https://doi.org/10.1038/onc.2014.305

10. Ito Y (2004) Oncogenic potential of the RUNX gene family: 'overview'. Oncogene. 3:4198-4208

11. Levanon D, Groner Y (2004) Structure and regulated expression of mammalian RUNX genes. Oncogene. 23(24):4211-4219. https://doi.org/10.1 038/s.onc.1207670

12. Wang L, Huang G, Zhao X, Hatlen MA, Vu L, Liu F, Nimer SD (2009) Posttranslational modifications of RUNX1 regulate its activity in the cell. Blood Cells Mol Dis 43(1):30-34. https://doi.org/10.1016/j.bemd.2009.03.005

13. Reikvam H, Hatfield K, Kittang AO, Hovland R, Bruserud $\varnothing$ (2011) Acute myeloid leukemia with the $t(8 ; 21)$ translocation: clinical consequences and biological implications. J Biomed Biotechnol 2011:1-23. https://doi.org/10.11 55/2011/104631

14. Motoda L, Osato M, Yamashita N, Jacob B, Chen LQ, Yanagida M, Ida H, Wee HJ, Sun AX, Taniuchi I, Littman D, Ito Y (2007) RUNXI protects hematopoietic stem/progenitor cells from oncogenic insult. Stem Cells 25(12):2976-2986. https://doi.org/10.1634/stemcells.2007-0061

15. Jacob B, Osato M, Yamashita N, Wang CQ, Taniuchi I, Littman DR, Asou N, Ito $Y(2010)$ Stem cell exhaustion due to RUNX1 deficiency is prevented by Evi5 activation in leukemogenesis. Blood 115(8):1610-1620. https://doi.org/1 0.1182/blood-2009-07-232249

16. Nishimoto N, Arai S, Ichikawa M, Nakagawa M, Goyama S, Kumano K, Takahashi T, Kamikubo Y, Imai Y, Kurokawa M (2011) Loss of AML1/RUNX1 accelerates the development of MLL-ENL leukemia through downregulation of p19ARF. Blood. 118(9):2541-2550. https://doi.org/10.1182/ blood-2010-10-315440

17. Kamikubo Y, Zhao L, Wunderlich M, Corpora T, Hyde RK, Paul TA, Kundu M, Garrett L, Compton S, Huang G, Wolff L, Ito Y, Bushweller J, Mulloy JC, Liu PP (2010) Accelerated leukemogenesis by truncated CBF $\beta$-SMMHC defective in high-affinity binding with RUNX1. Cancer Cell 17(5):455-468. https://doi. org/10.1016/j.ccr.2010.03.022

18. Behrens K, Triviai I, Schwieger M, Tekin N, Alawi M, Spohn M, Indenbirken D, Ziegler M, Müller U, Alexander WS, Stocking C (2016) RUNX1 downregulates stem cell and megakaryocytic transcription programs that support niche interactions. Blood. 127(26):3369-3381. https://doi.org/10.1182/blood-201509-668129 
19. Hebestreit K, Gröttrup S, Emden D, Veerkamp J, Ruckert C, Klein HU, MüllerTidow C, Dugas M (2012) Leukemia gene atlas - a public platform for integrative exploration of genome-wide molecular data. PLoS One 7:e39148. https://doi.org/10.1371/journal.pone.0039148

20. Kabel A, Zamzami F, Al-Talhi M, Al-Dwila K, Hamza R (2017) Acute myeloid leukemia: a focus on risk factors, clinical presentation, diagnosis and possible lines of management. Cancer Res Treat 5:62-67

21. Cheson BD, Bennett JM, Kopecky K, Büchner T, Willman CL, Estey EH et al (2003) Revised recommendations of the international working group for diagnosis, standardization of response criteria, treatment outcomes, and reporting standards for therapeutic trials in acute myeloid leukemia. J Clin Oncol 15(21):4642-4649

22. Frota IM, Leitão CC, Costa JJ, Brito IR, van den Hurk R, Silva JR (2011) Stability of housekeeping genes and expression of locally produced growth factors and hormone receptors in goat preantral follicles. Zygote 19(1):7183. https://doi.org/10.1017/S0967199410000080

23. Livak KJ, Schmittgen TD (2001) Analysis of relative gene expression data using real-time quantitative PCR and the $2-\Delta \Delta C T$ method. Methods. 25(4): 402-408. https://doi.org/10.1006/meth.2001.1262

24. Osato M (2004) Point mutations in the RUNX1/AML1 gene: another actor in RUNX leukemia. Oncogene. 23(24):4284-4296. https://doi.org/10.1038/sj. onc. 1207779

25. De Braekeleer E, Ferec C, De Braekeleer M (2009) RUNX1 translocations in malignant hemopathies. Anticancer Res 29(4):1031-1037

26. Niini T, Kanerva J, Vettenranta K, Saarinen-Pihkala UM, Knuutila S (2000) AML1 gene amplification: a novel finding in childhood acute lymphoblastic leukemia. Haematologica. 85(4):362-366

27. Wotton S, Stewart M, Blyth K, Vaillant F, Kilbey A, Neil JC, Cameron ER (2002) Proviral insertion indicates a dominant oncogenic role for RUNX1/AML-1 in T-cell lymphoma. Cancer Res 62(24):7181-7185

28. Osato M, Asou N, Abdalla E, Hoshino K, Yamasaki H, Okubo T, Suzushima H, Takatsuki K, Kanno T, Shigesada K, Ito Y (1999) Biallelic and heterozygous point mutations in the runt domain of the AML1/PEBP2. $B$ gene associated with myeloblastic leukemias. Blood. 93(6):1817-1824. https://doi.org/10.11 82/blood.V93.6.1817.406k36_1817_1824

29. Krygier A, Szmajda D, Żebrowska M, Jeleń A, Balcerczak E (2018) Expression levels of the runt-related. Oncol Lett 15:6733-6738

30. Fu L, Fu H, Tian L, Xu K, Hu K, Wang J et al (2016) High expression of RUNX1 is associated with poorer outcomes in cytogenetically normal acute myeloid leukemia. Oncotarget 29(7):15828

\section{Publisher's Note}

Springer Nature remains neutral with regard to jurisdictional claims in published maps and institutional affiliations.

\section{Submit your manuscript to a SpringerOpen ${ }^{\circ}$ journal and benefit from:}

- Convenient online submission

- Rigorous peer review

- Open access: articles freely available online

- High visibility within the field

- Retaining the copyright to your article

Submit your next manuscript at $\boldsymbol{\nabla}$ springeropen.com 